\title{
Clinical profile and management pattern of melasma patients in Western Nepal: A Hospital Based Study
}

\author{
B Dwari, S Palaian, A Poudel, S Prabhu
}

\section{Citation}

B Dwari, S Palaian, A Poudel, S Prabhu. Clinical profile and management pattern of melasma patients in Western Nepal: A Hospital Based Study. The Internet Journal of Dermatology. 2008 Volume 7 Number 1.

\begin{abstract}
Introduction: Melasma is an acquired hypermelanosis of sun-exposed areas. Melasma is much more common in women than in men. Women are affected in $90 \%$ of cases. The patient usually presents with tan to brown patches. Multiple factors have been postulated to involve in the etiology and pathogenesis of melasma including pregnancy, oral contraceptives, genetics, sun exposure, cosmetics and race.
\end{abstract}

Objectives: The objectives of the present studies are to study the demographic details of the melasma patients visiting the Manipal Teaching Hospital (MTH), to study the drugs used in management of melasma and to estimate the treatment cost to the patients.

Materials and methods: We went through the records of the patient at MTH and found out the number of patients suffering from melasma and other related data from 25th November 2005 to 30th November 2007. The data obtained were analyzed as per the study objectives.

Results: Altogether 107 patient files were included in the study. There were 75 (70.09\%) females and 32 (29.90\%) males (the total is 107). More than $50 \%$ of the patients were above the age 20 years. Most common site of occurrence of pigmentation was forehead accounting for $56.45 \%(n=70)$ of the total case followed by cheeks $12.09 \%(n=15)$. Altogether 290 drugs were used in the patients with a Mean $\square$ SD of $2.71 \square 0.89$ drugs per patient. The Mean $\square$ SD cost of medications was NRs $458 \square 251.36$.

Conclusion: The present study analyzed the clinical profile and treatment pattern of the melasma patients visiting MTH. Majority of the patients were of child bearing age. Sun screens were the most commonly employed medications followed by antioxidants $20(6.89 \%)$ and antibiotics $18(6.2 \%)$.

\section{INTRODUCTION}

Melasma is an acquired hypermelanosis of sun-exposed areas. It presents as symmetrical hyperpigmented macules and patches, which can be confluent or punctate. The cheeks, the upper lip, the chin, and the forehead are the most common locations, but it can occasionally occur in other sun-exposed locations. Chloasma is a synonymous term sometimes used to describe the occurrence of melasma during pregnancy. Melasma is much more common in women than in men. Women are affected in $90 \%$ of cases. Though commonly seen in women, it can also occur in men. The patient usually presents with tan to brown patches. ${ }_{3}$ Multiple factors have been postulated to involve in the etiology and pathogenesis of melasma including pregnancy, oral contraceptives, genetics, sun exposure, cosmetics and race. $_{4}$

Though melasma does not cause any major health related problems it severely affects social life, emotional well-being of the pateints. 5 The incidence of melasma in pregnant ladies with white skin is reported to be more than $50 \%$ of the cases. ${ }_{6}$ However, in India it was found to be nearly 10\%. 6 Though it affects the quality of life of the patients, there is only little awareness among the pregnant patients about the etiology of melasma. 7 The management of melasma usually involves hydroquinone in an alcoholic glycol or cream base applied over the skin. The literature regarding the clinical profile, management pattern and treatment outcomes of 
melasma is lacking in Nepal. Hence, we undertook the study with the following objectives.

Objectives: The study was conducted with the following objectives.

1. To study the demographic details of the melasma patients visiting the Manipal Teaching Hospital (MTH)

2. To study the drugs used in management of melasma

3. To study the cost spent by the patients in buying medications for melasma

Materials and methods: The materials and methods of the study are mentioned below.

Study site: Dermatology Out Patient Department of Manipal Teaching Hospital (MTH). It is a 700 bedded hospital located at Phulbari, Pokhara (having an average occupancy of around 300 beds)

Study type: Retrospective, cross sectional study.

Inclusion criteria: All the melasma patients visiting the dermatology outpatient department of Manipal Teaching hospital between the periods of $25 / 11 / 2005$ to $30 / 11 / 2007$ were included.

Method of data collection: We went through the records of the patient at MTH and found out the number of patients suffering from melasma and other related data from $25 / 11 / 2005$ to $30 / 11 / 2007$

Data analysis: The data obtained from the filled patient profile form were entered in the Microsoft excel programme and were analyzed. The SPSS version 9.0 was used to carry out the descriptive statistics.

\section{RESULTS}

Altogether 107 patient files were studied. The Mean SD age of the patients was 26.316 .10 years. The age and sex distribution of the patients are listed in Table 1.

\section{Figure 1}

Table 1: Age and sex distribution of the study population $(\mathrm{n}=107)$

\begin{tabular}{|l|l|c|c|}
\hline Parameters & \multicolumn{1}{|c|}{ Age group } & Number & Percentage \\
\hline Age distribution & $0-10$ & 0 & 0 \\
\cline { 2 - 4 } (years) & $11-20$ & 15 & 14.01 \\
\cline { 2 - 4 } & $21-30$ & 70 & 65.42 \\
\cline { 2 - 4 } & $31-40$ & 20 & 18.69 \\
\cline { 2 - 4 } & $41-50$ & 2 & 1.86 \\
\hline \multirow{3}{*}{ Sex } & Female & 75 & 70.09 \\
\cline { 2 - 4 } & Male & 32 & 29.90 \\
\hline
\end{tabular}

Type of pigmentation $(n=107)$ : It was found that 47 (43.925) of the pigmentations were malar followed by centrofacial $45(n=42.05 \%)$ and the type of pigmentation was not documented in $15(14.01 \%)$ of the patients.

Site of pigmentation $(n=124)$ : Most common site of occurrence of pigmentation was forehead. The details are listed in Table 2.

\section{Figure 2}

Table 2: Site of pigmentation

\begin{tabular}{|l|c|c|}
\hline \multicolumn{1}{|c|}{ Site } & Number & Percentage \\
\hline Forehead & 70 & 56.45 \\
\hline Cheeks & 15 & 12.09 \\
\hline Nose & 11 & 8.87 \\
\hline Nasal bridge & 8 & 6.45 \\
\hline Nape of neck & 3 & 2.41 \\
\hline Nasal dorsum & 3 & 2.41 \\
\hline Comea & 1 & 0.8 \\
\hline Eye lid & 1 & 0.8 \\
\hline Back of trunk & 1 & 0.8 \\
\hline Lumber area & 1 & 0.8 \\
\hline Nasal stream & 1 & 0.8 \\
\hline Scalp & 1 & 0.8 \\
\hline Upper back & 1 & 0.8 \\
\hline Unknown & 7 & 5.64 \\
\hline
\end{tabular}

Dosage form ( $\mathrm{n}=290)$ : Altogether 290 drugs were used in the patients with a Mean SD of 2.710 .89 drugs per patient. The details are listed in Table 3. 


\section{Figure 3}

Table 3: Dosage form $(\mathrm{n}=291)$

\begin{tabular}{|l|c|c|}
\hline \multicolumn{1}{|c|}{ Dosage form } & Number & Percentage \\
\hline Lotion & 139 & 47.93 \\
\hline Cream & 111 & 38.27 \\
\hline Gel & 14 & 4.82 \\
\hline Tablet & 12 & 4.13 \\
\hline Capsule & 8 & 2.75 \\
\hline Solution & 3 & 1.03 \\
\hline Soap & 2 & 0.68 \\
\hline Soap & 1 & 0.34 \\
\hline
\end{tabular}

Therapeutic category of the drugs used: Altogether 290 drugs were prescribed with a Mean SD of 2.710 .89 drugs per patient. The most commonly used drugs were sunscreen accounting for $75.51 \%(\mathrm{n}=219)$. The details are listed in Table 4.

\section{Figure 4}

Table 4: Therapeutic category $(n=290)$

\begin{tabular}{|l|c|c|}
\hline \multicolumn{1}{|c|}{ Therapeutic category } & Number & Percentage \\
\hline Antibiotic & 18 & 6.2 \\
\hline Sunscreen & 219 & 75.51 \\
\hline Antioxidants & 20 & 6.89 \\
\hline Antifungal & 13 & 4.48 \\
\hline Topical steroids & 11 & 3.79 \\
\hline Antihistaminic & 2 & 0.68 \\
\hline Corticosteroids & 2 & 0.68 \\
\hline Vitamins & 2 & 0.68 \\
\hline Antitussive & 1 & 0.34 \\
\hline Medicated soap & 1 & 0.34 \\
\hline Unknown & 1 & 0.34 \\
\hline
\end{tabular}

Top ten drugs used: The mostly prescribed drug in the hospital were the Eukroma cream $26.69 \%(n=63)$ followed by Elovera SPF lotion $25.42 \%(\mathrm{n}=60)$. The top ten drugs used are listed in Table 5.

\section{Figure 5}

Table 5: Top ten drugs prescribed $(n=290)$

\begin{tabular}{|c|c|c|}
\hline Drugs & Number & Percentage \\
\hline Clarithromycin gel & 8 & 3.38 \\
\hline $\begin{array}{l}\text { Aloe extract+ Vitamin E acetate+ } \\
\text { Octylmethoxycinnamate+ Oxybenzone }\end{array}$ & 60 & 25.42 \\
\hline Hydroquinone cream & 63 & 26.69 \\
\hline Fluticasone cream & 5 & 2.11 \\
\hline Glycolic acid + hydroquinone lotion & 37 & 15.67 \\
\hline $\begin{array}{lr}\text { Benzophenone } & + \text { Octyl } \\
\text { methoxycinnamate+silicon } & \text { oil } \\
\text { +titatnium trioxide lotion } & \end{array}$ & 10 & 4.23 \\
\hline $\begin{array}{l}\text { Hydroquinonw }+ \text { oxybenzone }+ \\
\text { octinoxite cream }\end{array}$ & 13 & 5.50 \\
\hline Retinoic acid A $0.025 \%$ & 12 & 5.08 \\
\hline $\begin{array}{l}\text { Octyl Methoxycinnamate+ avobenzene+ } \\
\text { oxybenzone }\end{array}$ & 20 & 8.47 \\
\hline Vitamins and Antioxidants & 8 & 3.38 \\
\hline
\end{tabular}

Outcome of the treatment: Among the total 107 patients nearly $35.51 \%(n=38)$ of the patient condition were improved. But more than $50 \%(n=61)$ of the patients condition were unknown.

Cost of medication ( $\mathrm{n}=107)$ : The Mean SD cost of medications during a single visit was NRs 458251.36 NRs. The cost of medication for 107 patients is listed in Table 6.

\section{Figure 6}

Table 6: Cost of medication

\begin{tabular}{|l|c|c|}
\hline \multicolumn{1}{|c|}{ Cost range } & Number & Percentage \\
\hline Up to 100 & 3 & 2.8 \\
\hline $101-200$ & 4 & 3.7 \\
\hline $201-300$ & 11 & 10.3 \\
\hline $301-400$ & 29 & 27.1 \\
\hline $401-500$ & 22 & 20.6 \\
\hline $501-600$ & 22 & 20.6 \\
\hline $601-700$ & 9 & 8.4 \\
\hline More than 700 & 7 & 6.5 \\
\hline
\end{tabular}

\section{DISCUSSION}

The present study identified the pattern of melasma in patients visiting the MTH, Pokhara. Melasma normally occurs mainly in pregnant women and in women taking anovular hormones. It is also known to occur in dark skin men. 8 In our study we found nearly one third of the cases to be men.

We found the mean age of the patients to be 26.3 years. In a study from Brazil the mean +/- SD age was $41.1+/-6.8$ years. ${ }_{9}$ However, the study included only women whereas our study included both the sexes. Another study from Brazil had the mean age of 42 years. ${ }_{10}$ It is well known that melasma 
occurs in women during their reproductive years. 1 In general persons with light brown skin types from regions of the world with intense sun exposure are much more prone to the development of melasma. ${ }_{11}$ Solar and ultraviolet exposures are the most crucial etiologic factors. Pregnancy, certain endocrine disorders and hormonal treatments, cosmetics, phototoxic drugs, and antiseizure medications are well-known inducing and exacerbating factors. ${ }_{12}$ In our study we did not evaluate the various parameters like UV exposure, drug history etc.

The common type of pigmentation was found to be malar followed by centrofacial. In our study we found the common sites of occurrence to be malar and centrofacial and extrafacial. In general, it commonly occurs in forehead, cheeks, temples, upper lip..$_{3}$ The goal of pharmacotherapy in melasma is to reduce morbidity and to prevent complications. ${ }_{1}$ The choice of proper treatment should take into account the type of melasma to be treated, the skin complexion of the patient, possible previous treatments, the expectations and compliance of the patient, and the season in which the treatment is started..$_{12}$

The use of broad-spectrum (UVA + UVB) sunscreen is important, as is topical hydroquinone, the most common treatment for melasma. Other lightening agents include retinoic acid (tretinoin) and azelaic acid. Combination therapies such as hydroquinone, tretinoin, and corticosteroids have been used in the treatment of melasma, and are thought to increase efficacy as compared with monotherapy ${ }_{13}$ In our study we found the most commonly used drugs to be sunscreen lotions. Chemical peels, laser treatments, and intense pulsed light therapy are additional therapeutic modalities that have been used to treat melasma. ${ }_{13}$ While managing the patients with melasma it is recommended that the treating physician must consider the devastating psychosocial impact of pigmentary imperfections within the realm of the benefits and risks associated with each treatment. ${ }_{14}$

\section{LIMITATIONS}

Our study had a few limitations. The study evaluated only a few parameters and also did not follow up the patients.
The present study analyzed the clinical profile and treatment pattern of the melasma patients visiting MTH. Majority of the patients were females and were of child bearing age. Sunscreens were the most commonly used medications and the drug therapy was associated with huge economic impact.

\section{CORRESPONDENCE TO}

Dr. Binayak Chandra Dwari MD Lecturer Department of Dermatology and Venereal Disease Manipal Teaching Hospital / Manipal College of Medical Sciences Pokhara, Nepal. E-mail: drbinayak@rediffmail.com Phone: +977 61 526416 Extn: 131

\section{References}

1. Montemarano AD. Melasma. e-Medicine. Available on http://www.emedicine.com/DERM/topic260.htm\#ref1

2. Sialy R, Hassan I, Kaur I, Dash RJ. Melasma in men: a hormonal profile. J Dermatol 2000; 27(1): 64-5

3. Lawley TJ, Yancey KB. Alterations in the skin. In:

Braunwald E, Fauci AS, Kasper DL, Hauser SL, Longo DL, Jameson JL (eds). Harrison's Principles of Internal Medicine.

15th edn. New York: McGraw-Hill; 2001. p. 305-9

4. Kauh YC, Zachian TF. Melasma. Adv Exp Med Biol. 1999; 455: 491-9.

5. Pawaskar MD, Parikh P, Markowski T, McMichael AJ,

Feldman SR, Balkrishnan R. Melasma and its impact on health-related quality of life in Hispanic women. J

Dermatolog Treat 2007; 18(1): 5-9

6 . Shivakumar V, Madhavamurthy P. Skin in pregnancy.

Indian Journal of Dermatology and Venerology.

7. Moin A, Jabery Z, Fallah N. Prevalence and awareness of melasma during pregnancy. Int J Dermatol. 2006 Mar; 45(3): $285-8$

8. Beers MH, Berkow R, Editors, The Merck Manual 17th edition, White House Station; Merck Research Laboratories 1999: 835-6.

9. Freitag FM, Cestari TF, Leopoldo LR, Paludo P, Boza JC. Effect of melasma on quality of life in a sample of women living in southern Brazil J Eur Acad Dermatol Venereol. 2008; 22(6): 655-62.

10. Cestari TF, Hexsel D, Viegas ML, et al. Validation of a melasma quality of life questionnaire for Brazilian Portuguese language: the MelasQoL-BP study and improvement of QoL of melasma patients after triple combination therapy. Br J Dermatol. 2006; 156 Suppl 1:13-20

11. Hughes BR. Melasma occurring in twin sisters. J Am Acad Dermatol. Nov 1987; 17: 841

12. Prignano F, Ortonne JP, Buggiani G, Lotti T.

Therapeutical approaches in melasma. Dermatol Clin. 2007 Jul; 25(3):337-42, viii.

13. Gupta AK, Gover MD, Nouri K, Taylor S. The treatment of melasma: a review of clinical trials. J Am Acad Dermatol. 2006 Dec; 55(6): 1048-65.

14. Grimes PE. Melasma. Etiologic and therapeutic considerations. Arch Dermatol 1995; 131(12): 1453-7

\section{CONCLUSION}




\section{Author Information}

Binayak Chandra Dwari, MD

Assistant Professor, Department of Dermatology and Venerology, Manipal Teaching Hospital

\section{Subish Palaian, M.Pharm}

Assistant Professor, Department of Pharmacology, Manipal College of Medical Sciences

\section{Arjun Poudel, B.Pharm}

Hospital and Clinical Pharmacist, Department of Hospital and Clinical Pharmacy, Manipal Teaching Hospital

Smitha Prabhu, MD

Associate Professor, Department of Dermatology, Kasturba Medical College 